\title{
LA CONSTITUCIÓN REPUBLICANA Y EL PUEBLO DE DEMONIOS. EL PROBLEMA DE LA CONSTITUCIÓN DEL ESTADO EN EL MARCO DE LA «HISTORIA-FILOSÓFICA» KANTIANA
}

\author{
The Republican Constitution and the People of Devils. \\ THE PROBLEM OF THE ESTABLISHMENT OF THE STATE \\ IN THE FRAMEWORK OF KANT'S «PHILOSOPHICAL-HISTORY»
}

\author{
Ileana P. Beade
}

\begin{abstract}
RESUMEN
En Idea para una historia universal en clave cosmopolita (1784), Kant sostiene que es imposible dar solución al problema de la constitución civil perfectamente justa, ya que los seres humanos, naturalmente inclinados a abusar de su libertad, son animales que necesitan de un señor, pero éste, a su vez, debería ser limitado por otro señor a fin de no incurrir en un ejercicio arbitrario del poder. Años más tarde, en Hacia la paz perpetua (1795), y a propósito de la las dificultades implicadas en la institución de una constitución republicana, señala que estas dificultades tienen solución, incluso para un pueblo de demonios (siempre que tengan entendimiento). Cabría pensar que el autor ha modificado su posición y se muestra ahora más optimista con respecto a la posibilidad de establecer una república perfecta. Sin embargo, intentaremos mostrar que Kant aborda, en cada uno de esos textos, problemas diversos: mientras en Idea se refiere a la posibilidad de una realización empírica de la república ideal, en Hacia la paz.perpetua considera el problema del establecimiento del Estado en general, cuestiones vinculadas pero, no obstante, diversas.
\end{abstract}

PALABRAS CLAVE: Libertad, Derecho, República, Estado, Insociable sociabilidad.

\section{ASBTRACT}

In Idea for a Universal History with a Cosmopolitan Aim (1784), Kant states that it is impossible to solve the problem of the perfect civil constitution, since the human being, naturally inclined towards an abusive use of his freedom, is an animal who needs a master - although this master should be limited, in turn, by another master, so that he does not abuse of his power. Nearly a decade later, in Perpetual peace (1795), he 
points out that, regarding the difficulties involved in a republican constitution, that those difficulties are solvable, even for a people of devils (as long as they have the power of understanding). We might think that the author has changed his position and feels more optimistic about the possibility of setting up the perfect republic. However, as I aim to show, Kant is actually addressing different problems in each of those texts: whereas the issue considered in Idea for a Universal History deals with the possibility of an empirical attainment of the ideal republic, in Perpetual peace he is concerned with the general problem of the establishment of the State. Both issues are, of course, connected, but they cannot be simply identified.

KEYWORDS: Freedom, Right, Republic, State, Unsociable sociability.

\section{INTRODUCCIÓN}

En Idea para una historia universal en clave cosmopolita [Idee zu einer allgemeinen Geschichte in weltbürgerlicher Absicht, 1784], Kant sostiene que el establecimiento de una constitución política justa constituye el mayor problema para la especie humana, problema cuya "solución perfecta" resulta imposible, ya que el hombre es un animal que necesita de un señor, pero éste necesitaría, a su vez, ser limitado por otro para obrar de modo justo, pues se halla sujeto a las mismas inclinaciones egoístas que afectan a resto de los individuos que integran la comunidad política (Kant, $\mathrm{IaG}, \mathrm{Ak}$. VIII, 23) ${ }^{1}$. Años más tarde, en Hacia la paz perpetua [Zum ewigen Frieden, 1795], y en el marco de una serie de consideraciones referidas a la constitución republicana, el autor señala que "el problema del establecimiento del Estado tiene solución [...], incluso para un pueblo de demonios (siempre que tengan entendimiento)" (ZeF, Ak. VIII, 366) ${ }^{2}$.

Como señala Guyer, cabría interpretar esta afirmación como un cambio de posición respecto de la posición asumida por Kant en IaG, texto en el que Kant parece negar la posibilidad de alcanzar una solución perfecta al problema de la

\footnotetext{
${ }^{1}$ La paginación citada corresponde a la Edición Académica de las obras kantianas: Kants gesammelte Schriften, Berlin, herasugegeben von der Königlich Preussischen Akademie der Wissenschaften, 1903s/1911, vol. I-IX. A esta edición aludimos bajo la abreviatura Ak., seguida del número de tomo indicado en números romanos, y el número de página en numeración arábiga, según el uso convencional en el ámbito de los estudios kantianos. A este escrito de 1784 haremos referencia bajo la abreviatura IaG.

${ }^{2}$ A este texto se hará referencia bajo la abreviatura ZeF.
} 
constitución civil justa ${ }^{3}$. Guyer sostiene que no se trata, en rigor, de un cambio de posición, pues Kant no afirma, en pasaje de ZeF lo que parece afirmar, a saber: que una buena constitución posible sería factible incluso para un conjunto de individuos auto-interesados. Una constitución política justa requiere —argumenta Guyer - que al menos ciertos individuos estén dispuestos a subordinar las máximas prudenciales a los principios de la moralidad; sin políticos morales — sin gobernantes que prioricen el cumplimiento del deber moral al interés individual o a las necesidades de la vida política — no sería posible una constitución civil justa, i.e. republicana.

Si bien consideramos relevantes las observaciones formuladas por Guyer, no coincidimos con la reconstrucción que propone acerca de la relación entre las afirmaciones formuladas en $\mathrm{IaG}$ y en $\mathrm{ZeF}$. Entendemos que, en este último escrito, Kant no está planteando que sea necesario contar con gobernantes moralmente virtuosos para que la república sea posible. El gobernante, al igual que cualquier otro individuo, se halla sujeto a una dialéctica natural entre inclinación y deber, y si una absoluta reconversión moral del mismo fuera indispensable para la constitución republicana, deberíamos renunciar a toda posibilidad de alcanzar una constitución tal (no ya de alcanzar la república perfecta, sino incluso de lograr una constitución republicana en general). No es esta, ciertamente, la posición de Kant, quien en diversos escritos exhorta a una progresiva aproximación a la república nouménica (entendida como ideal regulativo), aproximación que supone avanzar en formas de organización política cada vez más justas y equitativas, inspiradas en

\footnotetext{
3 "Here Kant seems to say that precisely because justice does not concern the «moral improvement of human beings» but requires only an external compliance with laws that can be motivated by «self-seeking inclinations», entirely self-seeking but sufficiently intelligent devils can solve the problem of establishing a just state by instituting threats of sanctions that will make it in their self-interest to keep their self-interest in check. Angels are not needed. Yet if devils can solve this problem, shouldn't human beings, even though they are made out of crooked timber and are therefore not angels, also be able to do so? Either Kant radically changed his view between the Sixth Proposition of 1784 and this passage in Perpetual Peace of 1795, so that the problem that he once thought could never be completely solved by human beings turns out to be solvable even by devils, or at least one of these passages cannot mean exactly what it first seems to mean. I will argue for the latter. [...] even though a just state does not require those who are ruled by its laws to be motivated by respect for morality alone, and thus does not depend upon the moral improvement of its subjects, it does require that those who institute and maintain the administration of the laws [...] be moved by morality rather than mere prudence. A just state can come into being only through what Kant calls later in Perpetual Peace «moral politicians»". Guyer (2009, 130-131).
} 
los principios del republicanismo ${ }^{4}$. En su reconstrucción del problema, Guyer no parece tener en cuenta de que se trata, en ambos escritos, de cuestiones vinculadas y, no obstante diversas: en IaG Kant reflexiona, entre otros aspectos, acerca de la posibilidad de un república absolutamente perfecta, mientras que en $\mathrm{ZeF}-\mathrm{y}$, más precisamente, en el pasaje en el que invoca la metáfora de un pueblo de demonios- el autor considera, en cambio, las condiciones de posibilidad de un Estado legítimo, fundado en principios republicanos, y declara que la virtud moral no es condición sine qua non de la buena constitución política. Coincidimos con el intérprete en que Kant no modifica su posición en ambos textos; sin embargo, no acordamos con la reconstrucción que propone a fin de salvar la aparente tensión entre las observaciones formuladas por el filósofo en $\mathrm{IaG}$ y, más tarde, en $\mathrm{ZeF}$. Como acabamos de señalar, Guyer no repara en que se trata, en rigor, de dos problemas diversos, cuestión que consideramos decisiva para la interpretación de ambos los pasajes cuyo análisis será será objeto del presente estudio.

Si bien cabría pensar que Kant ha modificado su posición respecto de la posibilidad de establecer una república perfecta, consideramos que el autor aborda, en ZeF, un problema diverso, referido a la posibilidad de regular una multiplicidad de voluntades individuales, de manera tal que sea posible garantizar el ejercicio de los derechos humanos fundamentales (Kant, ZeF, Ak. VIII, 366). Se trata aquí de un tópico recurrente en el desarrollo de la filosofía jurídico-política moderna: cómo y hasta dónde limitar la libertad individual, de manera tal que resulte conciliable con la libertad de otros, a través de una sujeción común a leyes públicas y a un poder coactivo que garantice el cumplimiento de las mismas. A continuación, intentaremos mostrar que Kant discute, en ambos textos, cuestiones diversas: el autor no modifica, en $\mathrm{ZeF}$, su posición respecto de la república ideal, a la que considera, en diversos escritos, como un ideal regulativo cuya realización empírica no es posible en sentido absoluto (tesis formulada en IaG y reiterada, años más tarde, en La metafísica de las costumbres [Die Metaphysike der Sitten, 1797] y en El conficto de las facultades [Der Streit der Fakultäten, 1798]). Si en ZeF sostiene que el problema del Estado tiene solución incluso para un pueblo de demonios, se trata aquí de la solución a otro problema, que no es ya, según veremos, el del establecimiento de la constitución civil perfectamente justa.

${ }^{4}$ Cf. Beade (2014, 473 y ss.). 


\section{LA CONSTITUCIÓN DEL ESTADO Y LA POSIBILIDAD \\ DE UN ESTADO IDEAL: DOS PROBLEMAS DIVERSOS \\ EN LA FILOSOFÍA PRÁCTICA KANTIANA}

La principal dificultad para el establecimiento de una constitución política en la que se administre universalmente el derecho constituye, según sostiene Kant en $\mathrm{IaG}$, el mayor desafío para la especie humana, a tal punto que la solución perfecta de este problema es imposible [ibre vollkommene Auflösung ist unmöglich] (Kant, IaG, Ak. VIII, 23). La dificultad reside, como adelantamos, en el hecho de que el hombre es un animal cuya libertad necesita ser limitada, pues tiende a abusar de ella y a exceptuarse de los mandatos morales; por tal motivo necesita sujetarse a leyes coactivas y a un poder que garantice su cumplimiento. Sin embargo, aquel a quien se delega el poder político debería estar sometido, a su vez, a un poder que lo limite, pues comparte con el resto de los seres humanos su inclinación al egoísmo, su codicia, su afán de dominio. El obstáculo principal para la posibilidad de una república perfecta reside así en la dificultad de hallar un jefe de la justicia pública que sea justo por sí mismo, sin dejar de ser hombre. Ya sea que se trate de un gobierno monárquico o de un régimen aristocrático, el problema subsiste: todos los seres humanos (incluso el gobernante) abusarán de su libertad en tanto no se sometan a un poder coactivo que los fuerce a obedecer las leyes (Kant, IaG, Ak. VIII, 23).

Se trata aquí, desde luego, de una dificultad estructural al orden político: aquellas disposiciones humanas que hacen necesario limitar la libertad y establecer un poder jurídico, tornan improbable el ejercicio justo del poder. En el Discurso sobre el origen y los fundamentos de la desigualdad entre los hombres [Discours sur l'origine et les fondements de l'inégalité parmi les hommes, 1755], Rousseau expresa esta dificultad con la agudeza que le es propia: "los vicios que hacen necesarios los establecimientos políticos son los mismos que hacen inevitable el abuso" (Rousseau, 279n). Este es el problema al que no puede darse, desde la perspectiva kantiana, una solución perfecta: el problema del gobierno absolutamente justo. Quien gobierna, y no se halla sometido, por tanto, a la coacción de otro que restrinja su libertad, no será capaz de limitarse a sí mismo; las inclinaciones humanas que hacen necesaria la sujeción común a un poder estatal son las mismas que tornan imposible la justicia perfecta.

En sus escritos morales, Kant se refiere de manera recurrente a la propensión natural del hombre a exceptuarse de la ley y satisfacer sus inclinaciones egoístas. En ZeF (y a propósito de la libertad de expresión que ha de concederse a los filósofos a fin de que puedan desarrollar su juicio crítico) alude al correlato político de esa premisas ético-antropológica, al afirmar que "no hay que esperar, ni desear, que los reyes filosofen ni que los filósofos sean reyes, porque la posesión del po- 
der daña inevitablemente el juicio de la razón” (Kant, ZeF, Ak. VIII, 369). Desde esta perspectiva, el ejercicio del poder político compromete de manera inevitable la autonomía requerida para el pensamiento racional y, como consecuencia de ello, afecta la integridad moral del individuo, que es resultado de la autonomía de la razón práctica. No obstante, Kant observa en ese mismo escrito que "el problema del establecimiento del Estado tiene solución [...], incluso para un pueblo de demonios (siempre que tengan entendimiento)" (ZeF, Ak. VIII, 366). A través de esta inquietante metáfora, intenta señalar que la república — como forma de organización política basada en la idea de derecho y en los principios de libertad, igualdad y la dependencia a leyes públicas - no requiere de individuos moralmente virtuosos, esto es, de sujetos capaces de deponer sus inclinaciones egoístas y actuar según los preceptos de la moralidad, sino sólo requiere de individuos racionales, proclives a obedecer las leyes públicas en tanto reconocen la necesidad de la coacción legal. Las inclinaciones egoístas no impiden que sujetos racionales adviertan la necesidad de leyes que limiten su libertad, pues se trata de seres capaces de comprender que sólo a través de la coacción legal puede ser garantizado el ejercicio de sus derechos básicos. La sujeción común a leyes públicas coactivas es la condición indispensable para el establecimiento de un orden jurídico, en cuyo marco los individuos puedan ejercer plenamente sus derechos y desarrollar sus capacidades. La moralidad individual —insistimos - no es requerida para la institución de dicho orden (sin perjuicio de que un orden político que reúna ciertas características pueda contribuir, en buena medida, al desarrollo de la moralidad).

Una rápida lectura de los pasajes a los que hemos hecho referencia podrían conducir a la conclusión de que Kant ha modificado su posición: mientras afirma, en $\mathrm{IaG}$, que el problema de la constitución civil justa no tiene solución, declara, en $\mathrm{ZeF}$, que el problema del establecimiento del Estado tiene solución (incluso para un pueblo de demonios). Sin embargo, no se trata aquí de un cambio de perspectiva, sino, tal como adelantamos, de dos problemas diversos. El primero de ellos, formulado en 1784, concierne a la posibilidad de una constitución civil perfectamente justa, es decir, a la realización empírica de la república ideal; el segundo problema, abordado en el escrito de 1795, alude por el contrario al establecimiento del Estado en general. Este problema consiste, según indica Kant, en:

"ordenar una multitud de seres racionales que, para su conservación, exigen conjuntamente leyes universales, aun cuando cada uno tienda en su interior a eludir la ley, y establecer su constitución de un modo tal que, aunque sus sentimientos particulares sean opuestos, den en contenerlos mutuamente de tal manera que el resultado de su conducta pública sea el mismo que el que sería de no tener esas malas inclinaciones. Un problema así debe tener solución" (Kant, Ak. VIII, 366). 
Tal problema debe tener solución, pues no requiere la perfección moral de los individuos; si esto último fuera un requisito, se trataría entonces de un problema sin solución, ya que las tendencias del ser humano a exceptuarse de los mandatos morales son naturales, y, por tanto, insuperables. El problema no es cómo lograr que los individuos que integran una comunidad política sean virtuosos, de manera tal que puedan conformar una constitución civil perfecta, sino que se trata, en cambio, de cómo regular la conducta de seres naturalmente dotados de una insociable sociabilidad (Kant, IaG, Ak. VIII, 20-21). La moralidad individual no es condición necesaria de la buena conducta civil ni es causa de ésta, sino que para ello basta con que los individuos actúen bien por temor a la coacción ${ }^{5}$. Más aún: Kant señala que sólo de una buena constitución política "hay que esperar la formación moral de un pueblo [die gute moralische Bildung eines Volk]" (Kant, ZeF, Ak, VIII, 366). Ahora bien, la formación moral de un pueblo no debe entenderse como una transformación radical en el carácter moral de los individuos, sino como el desarrollo progresivo de su disposición al cumplimiento de la ley moral (pese a la subsistencia de sus inclinaciones egoístas, las cuales, en tanto connaturales al ser humano, jamás lograrán ser absolutamente erradicadas). Atendiendo a nuestro objeto de análisis, no es necesario dilucidar en qué consistiría, propiamente, esta formación moral de un pueblo; bastará con señalar que la virtud moral no puede ser entendida como condición de la constitución política legítima, en la que puedan ser garantizados derechos individuales bajo leyes públicas. Este problema -el problema del Estado en general — no requiere, en síntesis, de hombres moralmente buenos; de allí que su solución sea posible "incluso para un pueblo de demonios".

A fin de matizar esta figura metafórica empleada por Kant, quizás cabría hablar, no ya de un pueblo de demonios [ein Volk von Teufeln], sino de individuos autointeresados ${ }^{6}$, proclives a satisfacer sus inclinaciones o impulsos egoístas y a exceptuarse a sí mismos del cumplimiento de la ley moral. El punto decisivo es que se

\footnotetext{
${ }^{5}$ En la sección siguiente haremos mayor referencia a la distinción entre eticidad y legalidad (entre deberes éticos y deberes jurídicos), tópico fundamental en el marco de la doctrina jurídica kantiana. ${ }^{6}$ Höffe señala que la expresión demonios, en tanto referida a los miembros de una comunidad política, ostenta un sentido puramente metodológico: lo que se quiere expresar a través de dicha noción es la necesidad de pensar el Estado como una institución cuya finalidad es coordinar la interacción de arbitrios individuales en los que no debe presuponerse actitudes altruistas, sino antes bien impulsos egoístas: si los individuos se hallasen naturalmente propensos a una conducta altruista, el Estado no sería necesario. En el marco de su justificación apriorística del Estado, Kant asume la naturaleza egoísta de los miembros que lo integran, sin que esta suposición tenga mayores alcances antropológicos o éticos. Höffe (1992, 125).
} 
trata aquí de individuos que poseen entendimiento, individuos cuya capacidad racional les permite comprender la necesidad de una sujeción común a la ley pública y al poder coactivo que la respalda. Es su condición de seres racionales lo que impulsa a los individuos a la sociabilidad: egoístas pero racionales, comprenden que sólo en el marco de la vida civil —y, por ende, bajo leyes públicas coactivas — podrán desarrollar plenamente sus capacidades y ejercer sus derechos. La naturaleza ha hecho a los seres humanos egoístas, ambiciosos, insociables, pero también los ha dotado de razón, confiriéndoles, de ese modo, una suerte de correctivo, una facultad que los induce a la sociabilidad. La conjunción de elementos insociables y sociables, la insociable sociabilidad, conduce a la institución de un orden jurídico, en el que los conflictos puedan ser regulados de manera no violenta, orden en el que puedan ser minimizados, controlados, los efectos perjudiciales de la insociabilidad. Kant se refiere a ello en IaG (Kant, Ak. VIII, 21-22), y años más tarde, insiste sobre este punto en $\mathrm{ZeF}$ :

"el mecanismo natural de contrarrestar las inclinaciones egoístas, que se oponen de modo natural también externamente, puede ser utilizado por la razón como un medio para hacerle sitio a su propio fin, al mandato legal y, por ende, para fomentar y garantizar la paz tanto interna como exterior, en la medida en que ésta descansa en el Estado mismo. Esto significa que la naturaleza quiere a toda costa que el derecho conserve, en último término, la supremacía (Kant, ZeF, Ak. VIII, 366-367).

Pese a las discrepancias entre algunas tesis formuladas en $\mathrm{IaG}$ y aquellas que serán desarrolladas, más tarde, en ZeF (discrepancias que se advierten, por ejemplo, respecto de la solución ofrecida, en cada caso, al problema del derecho cosmopolita $^{7}$ ), es posible identificar en ambos escritos aspectos cuyo tratamiento permanece inalterado en lo sustancial: en ambos textos se afirma, por ejemplo, que la Naturaleza opera como garante del progreso histórico, en la medida en que orienta a los hombres hacia el establecimiento de una constitución basada en los principios del republicanismo y del derecho cosmopolita ${ }^{8}$. En ambos escritos se discute la

\footnotetext{
${ }^{7}$ Cf. Kleingeld (2009, 171 y ss.); Kleingeld (2006, xv-xxiv); Kleingeld (2004, 304-325).

${ }^{8}$ No es nuestro objetivo dilucidar si esta Naturaleza, invocada por Kant en sus escritos histórico-filosóficos, debe ser interpretada como una fuerza trascendente que determina externamente el curso de los acontecimientos históricos, o bien como una naturaleza intrínseca o inmanente, es decir, como una determinación interna del desarrollo histórico posible a partir de las disposiciones naturales de la especie humana. Tanto la lectura teológica de la teleología histórica kantiana como la lectura secular encuentran, indudablemente, puntos de apoyo en las fuentes;
} 
cuestión de la factibilidad de una república ideal, se indaga acerca de las condiciones necesarias para una constitución política legítima, se hace referencia a las disposiciones humanas que conducen a la institución del orden jurídico-político, se examina la conexión entre el derecho político (estatal) y el derecho cosmopolita (interestatal), y se discuten tópicos específicos que se inscriben en el marco de la relación entre la ética, la antropología, la teoría política y la filosofía de la historia. Una rápida lectura de ambos textos permite constatar sin dificultad su afinidad temática; sin embargo, los problemas que Kant aborda en los pasajes puntuales a los que hemos hecho referencia en este trabajo no pueden ser identificados.

Como hemos señalado, en $\mathrm{IaG}$ no sólo se discute la cuestión general referida a las condiciones exigidas para el establecimiento de un Estado, sino que se formula el problema de si es posible alcanzar una constitución civil perfectamente justa. Dadas las características antropológicas inherentes al ser humano - modelado a partir de una madera tan torcida que nada absolutamente recto puede tallarse a partir de él (Kant, IaG, Ak. VIII, 23) — no es posible hallar un gobernante perfectamente justo, y es por ello que la naturaleza sólo nos impone una aproximación gradual a esa meta ideal, mas no su realización completa. Desde luego, Kant no rechaza absolutamente la posibilidad de una realización empírica de este ideal, tal rechazo sería incompatible con el carácter normativo que a atribuye a las ideas de la razón, ideales cuya realización es exigida por la razón práctica (no tendría sentido sostener que es imposible realizar aquello que la ley moral prescribe como deber incondicionado). El autor señala, en todo caso, la extrema dificultad implicada en la posibilidad de establecer una república perfecta: para ello sería necesario, no sólo contar con una idea precisa del fin buscado (lo cual requiere una reflexión teórica rigurosa, capaz de determinar con exactitud los principios fundamentales del orden civil), sino que se requeriría además de una amplia experiencia histórica, pacientemente desarrollada en el curso de varias generaciones; sería necesario, por otra parte, que la comunidad política estuviese integrada por individuos «de buena voluntad», que consientan vivir en una constitución tal (Kant, IaG, Ak. VIII, 23).

de allí que no resulte sencillo optar por una u otra interpretación. Por nuestra parte, consideramos que una interpretación inmanente de la Naturaleza invocada por Kant en sus escritos histórico-filosóficos resulta más acorde con los principios que dan sustento a su doctrina ética (vid. Beade 2011, 25-44). El desarrollo de nuestro objetivo no exige considerar esta cuestión, sino únicamente señalar que los problemas a los que se refiere Kant, en ambos escritos, no son equiparables; de allí que pueda sostener, en 1784, que la solución del problema de la constitución civil perfectamente justa es imposible, y afirmar más tarde, en el escrito de 1795, que el problema de cómo conciliar diversos arbitrios individuales tiene solución. 
Siendo improbable que la totalidad de estas condiciones puedan darse a la vez, no parece factible que los hombres logren instituir una forma de organización política perfectamente justa. El ejercicio del poder corrompe inevitablemente la autonomía de la razón, y es por ello que hallar un gobernante justo, un político moral, no es posible en sentido absoluto.

La sujeción de la política a los preceptos de la moral opera, no obstante, como un ideal, como un principio regulativo que nos orienta hacia la meta final del desarrollo histórico; pero no se trata aquí de una idea que pueda ser realizada en sentido pleno (insistimos: la constitución antropológica del ser humano no permite esta realización absoluta de la república ideal). La razón práctica impone, por consiguiente, la aproximación gradual a esta idea, y no su absoluta realización. En este sentido, creemos, sostiene Kant que la solución perfecta del problema de la constitución civil justa es imposible ${ }^{9}$.

\section{EL PROBLEMA DEL ESTADO Y SU RELACIÓN CON LAS NOCIONES DE DERECHO Y COACCIÓN}

En ZeF Kant sostiene que "el problema del establecimiento del Estado tiene solución, por duro que ello suene, incluso para un pueblo de demonios, siempre que tengan entendimiento" (Kant, ZeF, Ak. VIII, 366). Como indicamos en la sección previa, se trata aquí del problema de "la buena organización del Estado", cuestión que "efectivamente está en manos de los hombres", quienes, en virtud de su facultad racional, tienen la capacidad de regular sus fuerzas individuales, sus tendencias egoístas, de manera tal que "unas contengan los efectos perjudiciales de las otras o los eliminen: el resultado para la razón es que ocurre como si esas

\footnotetext{
${ }^{9}$ Kant parece vacilar respecto de este punto. Si bien sostiene que "esta tarea es la más difícil de todas y su solución perfecta es imposible" [ihre vollkommene Auflösung ist unmöglich]" (Kant, IaG, Ak. VIII, 23), un poco antes señala, sin embargo, que este problema "es el más difícil y el que más tardíamente será resuelto por la especie humana”, pues es improbable que se den simultáneamente la totalidad de las condiciones necesarias para alcanzar la constitución civil perfectamente justa. Sugiere así que es posible, si bien improbable, una realización de la república ideal, y "de ocurrir, sólo será muy tardíamente, tras muchos intentos fallidos". Sin embargo, a partir de la consideración de otros pasajes podemos concluir que el autor consideró imposible la realización empírica de la república perfecta, aunque el carácter normativo inherente a su teoría político-jurídica lo obliga a no desestimar como absolutamente imposible aquello que la razón práctica impone en carácter de deber: si considerásemos imposible satisfacer la demanda moral de la razón, careceríamos de los móviles necesarios para obrar en conformidad con tal demanda. A este punto haremos mayor referencia en la sección final.
} 
tendencias no existieran y el hombre se ve obligado a ser un buen ciudadano, aunque no precisamente un hombre malamente bueno" (Kant, ZeF, Ak. VIII, 366). El Estado es la institución que hace posible esta articulación u ordenamiento de las fuerzas individuales, permitiendo una coexistencia de arbitrios no concordantes en sus fines. El Estado es "la unión de un conjunto de hombre bajo leyes jurídicas" (Kant, MS, Ak. VI, 313), pero esta unión no es, desde luego, una coexistencia pacífica. A través del poder que se confiere al Estado — poder cuyo origen reside en la voluntad unida del pueblo (Kant, MS, Ak. VI, 315) ${ }^{10}$ — debe ser posible el ejercicio de los derechos naturales, y para ello es necesario establecer límites a la libertad individual, de manera tal ésta sea ejercida sin perjuicio de la libertad o el derecho de otros.

En La metafísica de las costumbres _ obra en la que hallamos la formulación más sistemática de la teoría kantiana del Estado-, Kant establece una conexión indisoluble entre las nociones de derecho y ley: el derecho no es, propiamente, derecho, sin la garantía provista por la ley, ya se trate de la ley como principio puro de la razón (como en el ámbito del derecho natural) o bien de la ley positiva (en el ámbito del derecho positivo o derecho civil). Ahora bien, derecho y ley se hallan estrechamente vinculados, a su vez, con el concepto de coacción: Kant sostiene, en efecto, que el derecho invoca o supone una obligación correlativa (MS, Ak. VI, 230), esto es, el derecho que se reconoce a un individuo supone, ante todo, una obligación para otros: la obligación de no interferir con ese derecho. Ahora bien, si el derecho de uno supone una obligación para otros — quienes se arrogan, recíprocamente, un derecho análogo—, el cumplimiento mutuo de esta obligación sólo puede ser garantizado a través de la coacción [Zwang]. Por consiguiente, "el derecho está ligado a la facultad de coaccionar [Das Recht ist mit der Befugniß zu zwingen verbunden]" (Kant, MS, Ak. VI, 231).

La coacción ejercida por las leyes y el Estado será legítima —es decir, acorde con la libertad de todos según leyes universales — toda vez que sea ejercida contra aquel que obstaculice la libertad de otros, es decir, contra aquel cuyos actos impidan a otros individuos perseguir sus propios fines. La coacción, entendida como obstáculo que se opone a quien pone obstáculos a la libertad de otros, es conforme

\footnotetext{
${ }^{10}$ Cabe señalar que, pese a la influencia insoslayable de Rousseau en la noción kantiana de una voluntad unida del pueblo (como origen último de todo poder soberano), la concepción de la soberanía desarrollada por ambos autores presenta diferencias fundamentales, especialmente en lo que concierne a la cuestión de una delegación del poder soberano, delegación que Rousseau rechaza, y que Kant, por el contrario, considera necesaria para la institución del poder estatal (Beade 2013, 59-84). Para un estudio comparativo entre las doctrinas políticas de Kant y Rousseau, vid. Hüning (107-120); Caranti (129-144); Carracedo (1988: 29-74).
} 
al derecho $(r e c h t)$, y en tal sentido señala Kant que al derecho está unida la facultad de coaccionar a quien lo viola; en efecto, reconocer el derecho de un individuo supone exigir a otros individuos que se abstengan de realizar acciones que pudiesen vulnerar ese derecho, so pena de coacción (Kant, MS, Ak. VI, 231). Sobre la base de estas premisas, Kant define el derecho estricto [stricte Recht] como "posibilidad de una coacción recíproca universal, concordante con la libertad de cada uno según leyes universales" (Kant, MS, Ak. VI, 232) ${ }^{11}$. Mientras que el derecho, en su acepción más general, es definido como el conjunto de condiciones que posibilitan la conciliación del arbitrio de cada uno con el arbitrio de otros según una ley universal de la libertad (Kant, MS, Ak. VI, 230), la definición del derecho estricto involucra, no sólo las nociones de ley y de libertad, sino asimismo la idea de una coacción recíproca universal, esto es, la idea de una coacción acorde a la libertad de cada uno según leyes universales. Kant añade que el derecho estricto, esto es, el derecho completamente externo - en cuyo marco el fundamento de determinación del arbitrio no involucra prescripción ética alguna-, se funda en la posibilidad de un coacción externa que obliga a todos a la observancia de determinados preceptos. Derecho estricto y coacción no solo se hallan así inmediatamente vinculados, sino que incluso se identifican: "derecho y facultad de coaccionar significan, pues, una y la misma cosa" (Kant, MS, Ak. VI, 232) ${ }^{12}$. En síntesis, la posibilidad de una coerción recíproca de carácter legal es lo que permite garantizar un orden en cuyo marco pueda ser ejercida la libertad; ésta, entendida como el derecho a la independencia con respecto al arbitrio constrictivo de otros, solo puede ser ejercida en el contexto de un orden legal de carácter coactivo

El trasfondo de esta discusión acerca de la conexión entre derecho y coacción está dado por la distinción entre libertad interna y libertad externa, a partir de la cual se articula el desarrollo de la metafísica moral kantiana, distinción que da lugar a la separación entre lo ético y lo jurídico, y como consecuencia de ello, a la división entre una doctrina de la virtud y una doctrina del derecho — desarrolladas, ambas, en La metafísica de las costumbres - En las secciones preliminares de esta obra se establece la distinción entre los deberes jurídicos, que solo pueden ser externos, y los deberes éticos, que incluyen no solo a las acciones internas sino a todos los deberes en general,

\footnotetext{
${ }^{11}$ Para un análisis de la matriz liberal implícita en esta concepción del derecho como capacidad de una coerción recíproca entre arbitrios individuales, vid. Pogge (139).

${ }^{12}$ Guyer señala que esta afirmación no sugiere una relación de identidad lógica entre libertad y coacción: Kant estaría afirmando aquí que oponer obstáculos a quien obstaculiza la libertad de otros hace posible el ejercicio de la libertad y en tal sentido el uso de la coacción sería una condición básica y fundamental para el ejercicio del derecho (Guyer 2004, 51).
} 
pues los deberes jurídicos pertenecen, en cuanto deberes, al dominio de la ética (Kant, MS, Ak. VI, 219). Kant señala que la doctrina del derecho y la doctrina de la virtud no difieren en cuanto a los deberes que prescriben, sino en el modo en que el móvil se vincula, en cada caso, con la ley: el móvil de la legislación ética solo puede ser interno, mientras que el móvil de la legislación jurídica es, ante todo, externo y está dado por la aversión a la coacción (ello no impide, sin embargo, que el cumplimiento de una ley jurídica obedecida solo por deber cobre un sentido ético ${ }^{13}$ ).

Más adelante observa que los deberes jurídicos son aquellos para los que es posible una legislación exterior, mientras que se denomina deberes éticos a aquellos que no pueden someterse a ninguna legislación externa, puesto que se dirigen a un fin que constituye, a la vez, un deber (Kant, MS, Ak. VI, 239). Dado que ninguna legislación puede ordenar que un individuo se proponga un fin determinado - pues la representación de un fin constituye un acto interno del ánimo-, los deberes éticos son internos y, por consiguiente, esencialmente ajenos al ámbito de la obligación jurídica. Si bien el modo en que Kant concibe la relación entre deberes éticos y jurídicos presenta algunas dificultades, interesa destacar aquí la conclusión a la que el autor arriba a partir de estas consideraciones, a saber: la idea de que la ética y el derecho no constituyen ámbitos absolutamente diferenciados, e incluso prescriben ciertos deberes que son comunes (como el deber de cumplir los contratos). Ética y derecho difieren, en todo caso, en el modo de obligación [die Art der Verpflichtung] que prescriben, siendo lo específico de la legislación ética el hecho de que ésta obliga a obedecer sus preceptos sencillamente porque son deberes (MS,

\footnotetext{
${ }^{13}$ Kant propone el siguiente ejemplo a fin de aclarar esta observación: al igual que la ley jurídica, la ética ordena el cumplimiento de los contratos contraídos, aunque sea propiamente la ley positiva la que nos compela a ello. En todo caso, "la ética enseña solo que, aun cuando se suprimiera el móvil que la legislación jurídica une con aquel deber — es decir, la coacción externa - la sola idea del deber basta como móvil" (MS, Ak. VI, 220). Si bien el cumplimiento de los contratos no es, en sentido estricto, un deber de virtud, sino un deber jurídico - a cuyo cumplimiento podemos ser externamente coaccionados-, cumplir con ese deber incluso cuando no pudiese temerse coacción alguna sería una acción virtuosa. El móvil que compele al cumplimiento de un contrato no es, en principio, interno, sino externo, a saber: el temor a la coacción que puede ser legítimamente ejercida por el poder público en caso de un incumplimiento del deber. Si un individuo cumpliese un contrato contraído aún en caso de no verse expuesto a coerción alguna, esa acción obedecería a una motivación puramente ética, en cuyo caso el cumplimiento del contrato constituiría un deber de virtud, y no ya un mero deber jurídico. El deber de virtud se diferencia del deber jurídico en que para este último es posible una coacción externa, mientras que el primero se funda en una auto-coacción libre (Kant, MS, Ak. VI, 383).
} 
Ak. VI, 220-221); mientras que lo específico de la legislación jurídica consiste en el cumplimiento de las normas por mera aversión a la coacción.

El ámbito de la libertad externa, esto es: aquél en el que rigen los deberes jurídicos, constituye el ámbito propiamente político-jurídico. Este ámbito es resultado de la necesidad de limitar la libertad de cada uno, de manera tal que resulte conciliable con la libertad de otros, bajo la sujeción común a leyes públicas coactivas. Este problema, el de la regulación de arbitrios diversos bajo leyes comunes o, puesto en otro términos, el problema de la legitimidad del Estado (Höffe 120)—, tiene solución. Así señala Kant, en $\mathrm{ZeF}$, que la solución al problema de la coexistencia de libertades individuales "está en manos de los hombres", quienes, en cuanto seres racionales, comprenden la necesidad de instituir un ordenamiento jurídico que permita garantizar a cada uno el ejercicio de sus derechos básicos. Es efectivamente posible regular las tendencias insociables del ser humano, de manera tal que éstas se contrarresten mutuamente, y resulten neutralizadas hasta cierto punto. El resultado de esta regulación —i.e. de este ordenamiento legal— es que cada individuo se verá forzado a actuar como un buen ciudadano, independientemente de sus cualidades morales particulares (Kant, ZeF, Ak. VIII, 366). El Estado, como unión de un conjunto de hombres bajo leyes jurídicas, hace posible la regulación del conflicto y la coexistencia pacífica de voluntades disímiles, sin necesidad de estar integrado por individuos moralmente virtuosos. Más aún: si los individuos que integran la comunidad civil fueran moralmente buenos, no necesitarían someterse a sí mismos a leyes públicas. El Estado, como tal, no requiere de seres humanos virtuosos; ni siquiera la república perfecta requeriría de tal condición, pues bastaría contar con un gobernante justo, capaz de administrar justicia sin abusar del poder que le ha sido conferido (Guyer 2009, 135-143).

\section{ALGUNAS CONSIDERACIONES FINALES}

A partir del análisis previo pueden ser formuladas algunas conclusiones acerca de las problemáticas a las que hemos hecho referencia, a saber: el problema de la realización empírica de la república ideal ( $\mathrm{IaG})$ y el problema del Estado en general ( $\mathrm{ZeF}$ ). Según indicamos, este segundo problema tiene solución: en efecto, resulta posible regular diversos arbitrios libres bajo leyes comunes, de tal modo que pueda garantizarse el ejercicio de ciertos derechos humanos fundamentales. Kant sostiene que esta regulación no sólo es posible, sino además necesaria, en el sentido de que la institución de un orden político-jurídico constituye un deber, un mandato incondicionado impuesto por la razón pura práctica. En el marco de la doctrina jurídica kantiana, la necesidad 
del Estado no es de carácter puramente pragmático, sino que asume, así pues, una significación esencialmente normativa (Kant, MS, Ak. VI, 237) ${ }^{14}$.

Respecto del primer problema (referido la posibilidad de establecer una constitución civil perfectamente justa), se trata de una cuestión que revela, una vez más, el carácter normativo de la teoría jurídica kantiana. Kant formula en IaG una tesis que reaparece, sin modificaciones sustanciales, en textos posteriores: la república ideal no puede ser realizada, como tal, en el plano empírico; pero esto no compromete, sin embargo, el carácter vinculante de esta idea. En el Apéndice a los Principios metafísicos del derecho (primera parte de La metafísica de las costumbres), observa que una constitución jurídica perfecta entre los hombres es una de las ideas "para las que no puede darse de modo adecuado ningún objeto en la experiencia" (MS, Ak. VI, 371). En el \$61 de ese mismo texto, y en relación con la idea de paz. perpetua (indisolublemente ligada a la noción de república y al proyecto de un derecho cosmopolita) sostiene que:

"la parperpetua (el fin último del derecho de gentes en su totalidad) es ciertamente una idea irrealizable. Pero los principios políticos que tienden a realizar tales alianzas entre los Estados, en cuanto sirven para acercarse continuamente al estado

\footnotetext{
${ }^{14} \mathrm{Si}$ bien algunos comentaristas destacan el sentido eminentemente teórico de la historia filosófica kantiana, indicando que en ella se trata de asumir una cierta perspectiva en la consideración de los hechos históricos (Wood 245-247), otros intérpretes enfatizan, por el contrario, su sentido esencialmente práctico y normativo (cf. Lindstedt 135 y ss.; Bittner 231 y ss.; Flikschuh 384 y ss.; Booth 63; Kaulbach 67). No es necesario considerar aquí los aspectos implicados en este debate, sino que basta con señalar que la dimensión teórica de la historia filosófica está ligada a la idea de unidad sistemática desarrollada por Kant en la primera Crítica y, más extensamente, en la Crítica de la facultad de juagar (Kleingeld, 2009: 175-176, Wood 249). Una idea es, para Kant, un concepto regulativo de la razón pura, una noción teleológica que permite a la razón representar la totalidad incondicionada en el ámbito de la investigación empírica de los fenómenos naturales. La concepción teleológica de la naturaleza -i.e. la idea de una naturaleza orientada a finesdesarrollada en la tercera Crítica, estaría anticipada ya en $\mathrm{IaG}$ y daría forma a la concepción kantiana de la historia (Guyer, 2006, 347-34; Ameriks 49, 57-59; Allison 24 y ss.; Kleingeld, 2006: xxii). Por nuestra parte, si bien reconocemos la conexión entre los aspectos teleológicos desarrollados en la primera y la tercera Crítica y el concepto de historia filosófica esbozado en $\mathrm{IaG}$, entendemos que la interpretación de dicho concepto exige atender, ante todo, a sus proyecciones prácticas. Así como la teoría debe regular toda práctica en general, así también una historia filosófica (en tanto que historia a priori) debe promover una transformación de la realidad empírica a partir de los principios de la razón pura práctica (Yovel 278 y ss.; Kleingeld xxii; Pinkard 218). Es esta dimensión práctica lo que define, a nuestro juicio, el aspecto fundamental de la historia filosófica kantiana (sin perjuicio de que puedan ser identificados ciertos principios teóricos que operan en su desarrollo).
} 
de paz perpetua, no lo son, sino que son sin duda realizables, en la medida en que tal aproximación es una tarea fundada en el deber y, por tanto, también en el derecho de los hombres y de los Estados" (MS, Ak, VI, 350).

La imposibilidad de realizar una idea de la razón pura práctica no socava el influjo que esa idea ejerce en tanto principio orientador de la praxis ${ }^{15}$. Basta con que no pueda demostrarse la imposibilidad de una idea de la razón práctica para que debamos asumirla como un deber:

"Si alguien no puede probar que algo es, puede intentar probar que no es. Pero si no lo consigue de ninguna de ambas formas (cosa que sucede a menudo), puede todavía preguntar si le interesa aceptar (como hipótesis) una cosa u otra, y esto con un propósito teórico o práctico, es decir, o bien para explicarse simplemente un cierto fenómeno [..] o bien para alcanzar un determinado fin, que puede ser a su vez pragmático (un simple fin técnico) o moral, es decir, un fin tal que la máxima de proponérselo es un deber. Es evidente que aquí no se convierte en deber aceptar (suppositio) que el fin sea realizable, cosa que es un juicio meramente teórico y problemático en este sentido, porque no hay obligación alguna de ello (de creer algo); sino que a lo que nos obliga un deber es a actuar según la idea de aquel fin, aunque no exista la menor probabilidad teórica de que pueda ser realizado, pero no obstante tampoco pueda demostrarse su imposibilidad. Ahora bien, la razón práctico-moral expresa en nosotros su veto irrevocable: no debe haber guerra; ni guerra entre tú y yo en el estado de naturaleza, ni guerra entre nosotros como Estados [...]; porque éste no es el modo en que cada uno debe procurar su derecho. Por tanto, la cuestión no es ya la de saber si la paz perpetua es algo o es un absurdo, y si nos engañamos en nuestro juicio teórico si suponemos lo primero; sino que hemos de actuar con vistas a su establecimiento como si fuera algo que a lo mejor no es, y elaborar la constitución que nos parezca más idónea para lograrla [...]. $\mathrm{Y}$ aunque esto último - lo que concierne al cumplimiento de este propósitoquedara como como un deseo irrealizable, no nos engañaríamos ciertamente al aceptar la máxima de obrar continuamente en esta dirección; porque esto es un deber" (Kant, MS, Ak. VI, 354) ${ }^{16}$.

${ }^{15}$ En Teoría y práctica Kant se refiere al carácter vinculante de las ideas de la razón introduciendo el concepto de una realidad objetiva (práctica) correspondiente a tales ideas: las ideas de contrato originario, república, derecho cosmopolita o pazperpetua poseen realidad objetiva (práctica), en la medida en que la razón se representa la realización fáctica de tales ideas como un deber incondicionado (Kant, TP, Ak. VIII, 297).

${ }^{16}$ En Teoría y práctica señala Kant: "Se me permitirá, pues, admitir que [...] el género humano se halla en continuo avance [...]. No tengo necesidad de demostrar esta suposición; es el adversario de ella quien ha de proporcionar una prueba. Porque yo me apoyo en un deber para 
Kant afirma que debemos actuar de acuerdo con el ideal de una paz perpetua, incluso en caso de que no existiese la menor probabilidad teórica de que este ideal pudiese ser efectivamente realizado ${ }^{17}$. Si bien ciertas ideas no pueden constituirse como objetos de la razón teórica —i.e. no pueden ser conocidas —, son, sin embargo, absolutamente vinculantes para la razón práctica ${ }^{18}$. En un pasaje de La contienda de las facultades (1798), Kant introduce una elocuente distinción entre la república fenoménica y la república nouménica que ilustra esta noción fundamental de su filosofía práctica:

mí innato, consistente en que cada miembro de la serie de generaciones [...] actúe sobre la posteridad de tal manera que ésta se haga cada vez mejor [...]. Por incierto que me resulte y que me siga resultando siempre si cabe esperar lo mejor para el género humano, esto no puede destruir, sin embargo, la máxima — ni, por tanto, la necesidad de presuponerla con miras prácticas- de que tal cosa es factible” (Kant, TP, Ak. VIII, 308-309). Si prescindiésemos de la "esperanza de tiempos mejores", no hallaríamos motivación para actuar de modo tal de que nuestras acciones contribuyan al progreso. Es por ello que ningún argumento fundado en la experiencia o en datos empíricos resulta suficiente para hacernos desistir de la esperanza el progreso futuro. En el caso de un propósito o fin moral, "basta con que no se haya demostrado la imposibilidad de su realización para que constituya un deber" (Kant, TP, Ak. VIII, 310). ${ }^{17} \mathrm{Al}$ respecto señala Kersting: "neither the normative guidance of political philosophy nor the work of reform in history is finished with the attainment of a real republic" (Kersting 361). Sin embargo, la imposibilidad de una realización plena de la república perfecta no compromete el carácter vinculante implícito en la idea de república. Lo mismo cabe afirmar respecto de la idea (o ideal) de una pazperpetua entre los Estados: "Kant does not expect that a stable world federation that always ward off war can ever be attained. Nevertheless, perpetual peace is a necessary guiding idea for politics. [...]. In the demand for perpetual peace practical reason is not being fantastic, but consistent. Just as the subjection of politics to the idea of the republic is practically necessary, so the subjection of politics to the idea of perpetual peace is also a duty. Both demands, the internal political demand of eventual republicanization and the external political demand of the unremitting effort to establish peace, are grounded in one and the same innate human right. The rightful legislation of pure practical reason categorically demands that we work for perpetual peace" (Kersting, 2006: 363-364). Flikschuh arriba a una conclusión análoga en lo concerniente a la idea de derecho: "We approximate the end of Right by means of the empirical institutionalization of relations of Right at the state, interstate and cosmopolitan levels. Strictly speaking, however, the "Right of humanity" is empirically nonrealizable. It is, again, a noumenal idea of reason that exceeds all possibility of its empirical manifestation or institutionalization" (Flikschuh 395).

${ }^{18}$ Las ideas constituyen representaciones para las cuales no puede hallarse en la experiencia objeto correspondiente alguno; no son objeto de un conocimiento teórico, pero ejercen, no obstante, una función regulativa, tanto en el ámbito correspondiente a la organización sistemática del conocimiento empírico, como en aquel que concierne a cuestiones práctico-morales. 
"La idea de una constitución en consonancia con el derecho natural de los hombres, a saber, que quienes obedecen la ley deben ser simultáneamente colegisladores, se halla a la base de todas las formas políticas y la comunidad conforme a ella por medio de conceptos puros de la razón, que se denomina ideal platónico (respublica noumenon), no es una vana quimera, sino la norma eterna para cualquier constitución civil en general y el alejamiento de toda guerra. Una sociedad civil organizada de acuerdo con ella supone su ejemplificación en la experiencia según leyes de la libertad (respublica phaenomenon) y sólo puede conseguirse arduamente, tras muchas guerras y hostilidades; sin embargo, una vez que se ha conseguido grosso modo, esta constitución se cualifica como la mejor entre todas por mantener alejada la guerra, destructora de todo bien" (Kant, SF, Ak. VII, 90-91).

Kant caracteriza aquí a la república como un ideal platónico, como república nouménica, calificativo que podría interpretarse, en este contexto, como sinónimo de concebible o pensable (por oposición a cognoscible); en efecto, una república tal no es cognoscible sino pensable, en el sentido de que no puede ser jamás dada en ninguna experiencia posible. La razón, en su uso teórico, no puede garantizar la posibilidad efectiva de la república ideal — como tampoco puede garantizar que los hombres efectivamente progresen hacia un estado de mayor perfección-; sin embargo, ello no es obstáculo para que la razón práctica imponga la representación de este ideal como un deber incondicionado (Lindstedt 145; Kuhen 91; Beade 473 y ss.). En tal sentido — - y sólo en éste — la razón práctica trasciende las limitaciones inherentes a la razón teórica, pues no necesita sujetarse a aquello que es efectivamente dado en la experiencia, sino que sólo le concierne aquello que debe ser dado, aquello cuya realización es impuesto por la razón como un deber. En este ámbito de lo que debe suceder (radicalmente diverso del ámbito de lo que de hecho sucede) se inscriben, pues, la idea de república, la noción de una pazperpetua entre los Estados, o el ideal de un progreso ininterrumpido del género humano hacia un estado de mayor perfección.

Para concluir, quisiéramos recordar un pasaje de un texto perteneciente al precrítico, Los sueños de un visionario explicados por los sueños de la metafísica [Träume eines Geistersehers, erläutert durch Träume der Metaphysik,1766], en el que Kant se refiere a las ventajas (que acaso podrían ser — erróneamente- consideradas como inexactitudes) inherentes al uso práctico de la razón. Allí señala que: "la balanza del entendimiento no es totalmente imparcial y un brazo suyo, el que lleva la inscripción esperanza del futuro [Hoffnung der Zukunft, posee una ventaja mecánica que hace que incluso débiles razones instaladas en su plato levanten del otro especulaciones que de por sí tienen un mayor peso. Esta es la única inexactitud que no puedo suprimir y que, de hecho, tampoco quiero suprimir" (Kant, TG, Ak. II, 349-350). Este optimismo moral, cu- 
yos orígenes podrían ser rastreados ya en la ética socrática, asume un sentido inédito en el ámbito de la filosofía kantiana de la historia, en la medida en que se funda en una concepción normativa del progreso. La confianza en el avance del género humano hacia un estado de mayor perfección no es, desde luego, algo que podamos inferir a partir de la experiencia histórica, sino una idea, un idea cuya realización cuanto menos parcial_ es impuesta, por la razón práctica, como un deber.

\section{Ileana P. Beade CONICET - Universidad de Rosario ileanabeade@yahoo.com.ar}

\section{BIBLIOGRAFÍA}

Allison, H. (2009): “Teleology and history in Kant: the critical foundations of Kant's philosophy of history", en A. O Rorty; J. Schmidt (eds.), Kant's Idea for a Universal History with a Cosmopolitan Aim. A Critical Guide, Cambridge: Cambridge University Press, pp. 24-45.

AMERIKS, K.(2009): “The purposive development of human capacities", en A. O Rorty; J. Schmidt (eds.), Kant's Idea for a Universal History with a Cosmopolitan Aim. A Critical Guide, Cambridge: Cambridge University Press, pp. 46-67.

BEADE, I. (2011): "Libertad y naturaleza en la filosofía kantiana de la Historia", Daimon, $\mathrm{n}^{\circ} 54$, pp. 25-44.

- (2013): "El concepto kantiano de voluntad pública y su relación con la noción rousseauniana de voluntad general', Estudos Kantianos, no 1.2, pp. 59-84.

- (2014): "Acerca del carácter regulativo de las ideas de la razón en el marco de la doctrina jurídico-política kantiana", Revista Portuguesa de Filosofía, vol. 70, n² 2-3, pp. 473-492.

BitTNer, R. (2009): "Philosophy helps history, en A. O Rorty; J. Schmidt (eds.), Kant's Idea for a Universal History with a Cosmopolitan Aim. A Critical Guide, Cambridge: Cambridge University Press, pp. 231-249.

Booth, W. (1983): "Reason and History: Kant's Other Copernican Revolution”, KantStudien, $\mathrm{n}^{\circ} 74$, pp. 56-71.

CARANTI, L. (2013): “Two faces of Republicanism: Rousseau and Kant”, Estudos Kantianos, vol.1, no 2, pp. 129-144.

FLIKSCHUH, K. (2006): “Reason and Nature: Kant's Teleological Argument in Perpetual Peace", en G. Bird, A Companion to Kant, Oxford: Blackwell Publishing, pp. 383-396.

FÖrSTER, E. (2009): “The hidden plan of nature", en A. O Rorty; J. Schmidt (eds.), Kant's Idea for a Universal History with a Cosmopolitan Aim. A Critical Guide, Cambridge: Cambridge University Press, pp. 187-199.

GuYER, P. (2004): “Kant's Deductions of the Principles of Rights", en M. Timmons, Mark (ed.), Kant's Metaphisics of Morals. Interpretative Essays", Oxford: University Press, New York, pp. 23-63. 
GUYER, P. (2006): Kant, New York: Routledge,

- (2009): "The crooked timber of mankind", en A. O Rorty; J. Schmidt (eds.), Kant's

Idea for a Universal History with a Cosmopolitan Aim. A Critical Guide, Cambridge: Cambridge University Press, pp. 129-149.

HöfFE, O. (1992): "Even a Nation of Devils Needs the State: the Dilemma of Natural Justice",en H. Williams (ed.), Essays on Kant's Political Philosophy, Chicago: The University of Chicago Press, pp. 120-142.

HÜNING, D. (2013): “«Rousseau set me aright». The Legacy of Rousseau in Kant's Legal and Political Philosophy and the Idealization of the Volonté Générale”, Estudios Kantianos, vol. 1, no 2 , pp. 107-120.

KaNT, I. (1902ss.): Kant's gesammelte Schriften, hrsg. von der Königlich Preussischen, bzw. der Deutschen Akademie der Wissenschaften, Berlín et alia.

- (1989): La metafísica de las costumbres [Die Metaphysike der Sitten, 1796/1797], traducción de A. Cortina Orts y J. Conill Sancho, Madrid: Tecnos.

- (1993) Teoría y práctica [Über den Gemeinspruch: Das mag in der Theorie richtig sein taugt aber nicht für die Praxis, 1793], traducción de J. M. Palacios, M. F. Pérez López y R. Rodríguez Aramayo, Madrid: Tecnos.

- (1994): Ideas para una Historia Universal en clave cosmopolita [Idee zu einer allgemeinen Geschichte in weltbürgerlicher Absicht, 1784] y otros escritos sobre Filosofía de la Historia, traducción de C. Roldán Panadero y R. Rodríguez Aramayo, Madrid: Tecnos.

- (1994): Los sueños de un visionario explicados por los sueños de la metafísica [Träume eines Geistersehers, erläutert durch Träume der Metaphysik,1766], traducción de P. Chacón e I. Reguera, Madrid: Alianza.

- (1996): Sobre la pazperpetua [Zum ewigen Frieden, 1795], traducción de J. Abellán, Madrid: Tecnos.

- (2007): Crítica de la razón pura [Kritik der reinen Vernunft, 1781/1787], traducción de M. Caimi, Buenos Aires: Colihue.

KaulBaCH, F. (1975): “Welchen Nutzen gibt Kant der Geschichtsphilosophie?”, KantStudien, $\mathrm{n}^{\circ}$ 66, pp. 65-84.

Kersting, W. (1992): “Kant's Concept of the State”, en H. Williams (ed.), Essays on Kant's Political Philosophy, United Kindom: The University of Chicago Press, pp. 143-165.

KLEINGELD, P. (2004): “Approaching Perpetual Peace: Kant's Defence of a League of States and his Ideal of a World Federation", European Journal of Philosophy, vol. XII, no 3, pp. 304-325.

- (2006): "Kant on Politics, Peace, and History", en P. Kleingeld (ed.), Toward Perpetual Peace and other Writings on Politics, Peace and History, New York: Yale University Press, pp. xv-xxiv.

- (2009), "Kant's changing cosmopolitanism", en A. O. Rorty; J. Schmidt (eds.), Kant's Idea for a Universal History with a Cosmopolitan Aim. A Critical Guide, Cambridge: Cambridge University Press, pp. 171-186. 
KuEHN, M. (2009): "Reason as a species characteristic”, en A. O. Rorty; J. Schmidt (eds.), Kant's Idea for a Universal History with a Cosmopolitan Aim. A Critical Guide, Cambridge: Cambridge University Press, pp. 68-93.

LindsteDT, D. (1999): "Kant: Progress in Universal History as a Postulate of Practical Reason”, Kant-Studien, no 90, pp. 129-147.

PINKARD, T. (2009): Norms, facts, and the philosophy of history", en A. O. Rorty; J. Schmidt (eds.), Kant's Idea for a Universal History with a Cosmopolitan Aim. A Critical Guide, Cambridge: Cambridge University Press, pp. 216-230.

PoGgE, Th. (2004): “Is Kant's Rechtslehre a 'Comprehensive Liberalism'?, en M. Timmons (ed.), Kant's Metaphisics of Morals. Interpretative Essays”, New York: Oxford University Press, pp. 133-158.

Rousseau, J. J. (1996): Discurso sobre el origen y los fundamentos de la desigualdad entre los hombres [Discours sur l'origine et les fondements de l'inégalité parmi les hommes, 1755], traducción de M. Armiño, Madrid: Alianza.

Rubio CARracedo, J. (1988): "El influjo de Rousseau en la filosofía práctica de Kant", en E. Guisán (ed.), Esplendor y miseria de la ética kantiana, Barcelona: Anthropos, pp. 29-74.

Wood, A. (2006): “Kant's Philosophy of History”, en P. Kleingeld (ed.), Toward Perpetual Peace and other Writings on Politics, Peace and History, New York: Yale University Press, pp. 243-265.

Yovel, Y. (1980): Kant and the Philosophy of History, Princeton: Princeton University Press. 